International Journal of Anesthesiology \& Research (IJAR)

ISSN 2332-2780

\title{
Pathophysiology of Complex Regional Pain Syndrome Type I: Update
}

Martino Bussa ${ }^{1 *}$, M. Lucia ${ }^{2}$, A. Mascaro ${ }^{2}$ L. Cuffaro ${ }^{3}$, T. Bontà2 ${ }^{2}$ S. Rinaldi ${ }^{4}$

Research Article

${ }^{1}$ O.U. of Anesthesia, Intensive Care and Pain Therapy of Sant'Antonio Abate Hospital, Erice Casa Santa, Trapani, Italy.

${ }^{2}$ O.U. of Anesthesia, Intensive Care and Pain Therapy of Azienda Ospedaliera Ospedali Riuniti Villa Sofia Cervello, Palermo, Italy.

${ }^{3}$ Anesthesiology, Intensive Care and Pain Therapy Department, Catholic University, Medical School, Rome, Italy.

${ }^{4}$ Plastic and Reconstructive Surgery Department, University 'Sapienza' of Rome, Italy.

\begin{abstract}
Background: Complex regional pain syndrome type I (CRPS I), also known as reflex sympathetic dystrophy (RSD), develops as disabling painful disorder following a trauma or surgery to a limb. We provide a review based on the current literature concerning the epidemiology and pathophysiology of CRPS I. Possible pathophysiological mechanisms of CRPS I are inflammation, sympathetic-afferent coupling and cortical changes.

Methods: A literature search was conducted using, as electronic bibliographic database, Medline from 1980 until today.

Results: CRPS I is a multifactorial disorder with complex aetiology and pathogenesis.

Conclusions: The pathophysiology of CRPS I is complex and may change during its course. CRPS I is more than a peripheral disease because peripheral mechanisms such as neurogenic inflammation and sympathetic-afferent coupling inconclusively explain its pathophysiology. CRPS I is a pain disorder involving the somatosensory, the somatomotor and the sympathetic nervous systems. Genetic findings suggest there might be a predisposition to CRPS I and it has been confirmed in multiple studies that psychological factors are not predictors for the development of CRPS I. The complexity and diversity of the mechanisms involved will be liable to the heterogeneity of the clinical presentation and may explain the difficulty of achieving an evidence-based treatment of CRPS I.
\end{abstract}

Keywords: Complex Regional Pain Syndrome; Reflex Sympathetic Dystrophy; Neurogenic Inflammation; Sympathetic Nervous System; Neuropathic Pain.

\section{*Corresponding Author:}

Martino Bussa MD,

O.U. of Anesthesia, Intensive Care and Pain Therapy of Sant'Antonio Abate Hospital, Erice Casa Santa, Trapani, C/da Duchessa 126, 91014 Castellammare del Golfo (TP), Italy.

Tel: +39-339-5865615

E-mail: bussamartino@gmail.com

Received: June 26, 2015

Accepted: July 22, 2015

Published: August 03, 2015

Citation: Martino Bussa et al., (2015) Pathophysiology of Complex Regional Pain Syndrome Type I: Update. Int J Anesth Res. 3(7), 141-146.

Copyright: Martino Bussa ${ }^{\circ}$ 2015. This is an open-access article distributed under the terms of the Creative Commons Attribution License, which permits unrestricted use, distribution and reproduction in any medium, provided the original author and source are credited.

\section{Introduction}

Complex regional pain syndrome Type I (CRPS I), previously known as reflex sympathetic dystrophy (RSD), is a painful and disabling disorder that can occur in an extremity after a minor trauma or surgery or may develop spontaneously [1-3]. This topical review describes the epidemiology and focuses on updated pathophysiologic mechanisms of CRPS I. The purpose of this review is to contribute to the dissemination of knowledge among clinicians of pathophysiological mechanisms since, an increased understanding of the pathogenesis of CRPS I provides the possibility to develop mechanism-based treatments.

\section{Methods}

A search for published articles, focusing on epidemiology and pathophysiology, was performed using, as electronic bibliographic database, Medline from 1980 until present. For each pathophysiological mechanism, a separate search was conducted in Medline, using the query 'complex regional pain syndrome Type I' combined with one of the following queries: for autonomic nervous system dysfunction was used 'sympathetic nervous system' or 'sympathetically maintained pain'; for inflammation, 'inflammation' or 'neurogenic inflammation' or 'neuropeptide' or 'hypoxia'; for central sensitization, 'hyperalgesia' or 'wind-up' or 'NMDA receptor' or 'glial cells'; for brain plasticity, 'cortical reorganization' or 'referred sensations' or 'hemisensory impairment'; for psychological factors, 'psychology' or 'psychiatric' or 'behavior'. With the purpose of overviewing the known risk factors, the query 'complex regional pain syndrome Type I' was combined with the following terms: 'incidence', 'prevalence', 'genetic factors'. Abstracts were screened manually, and full test papers were considered if the abstract suggested an experimental or observational study focused on the pathogenesis of CRPS I or a review concerning one or more pathogenetic mechanisms or an association between CRPS I and risk factors. Only articles written in English were included. 


\section{Historical Background}

In 1946, Evans coined the term 'reflex sympathetic dystrophy' (RSD) based on the hypothesis that the sympathetic dysfunction was involved in generation and perpetuation of pain [1]. In 1986, Roberts introduced the term 'sympathetically maintained pain' (SMP) as a synonym of RSD [1]. However, the traditional concept of the involvement of the sympathetic nervous system has been questioned because many patients do not respond to sympathetic blockade. Also, as pain is maintained by the sympathetic efferent innervation or by circulating catecholamines in only a subset of patients with CRPS I, the term SMP should be restricted to the aspect of pain that is relieved by specific sympatholytic procedures. So, the term 'reflex sympathetic dystrophy' was abandoned and, in 1993, a Special Consensus Workshop of the International Association for the Study of Pain (IASP) introduced the term 'CRPS' to describe this painful period of chronic disturbances, which are also associated with vasomotor and sudomotor changes, with the aim of improving recognition of the disease and facilitating treatment outcome [3]. CRPS is classified as Type I (CRPS I) when it develops after a minor trauma or a small nerve injury and as type II (CRPS II), once known as causalgia, when it follows a demonstrable nerve injury [3].

\section{Epidemiology}

CRPS I occurs more frequently in females than in males (2,3:1$4: 1)[4,5]$. In adults, the upper limbs are more often affected than the lower limbs. CRPS I most commonly affects a single limb. The onset of CRPS I is usually linked to a history of fractures, contusions/sprains and surgery. In approximately $10 \%$ of cases [6]. CRPS I develops spontaneously. Data on the incidence of CRPS I are scarce. Sandroni and colleagues [5] were the first to evaluate the incidence of CRPS I in the general population (Olmsted County, USA) and they calculated an incidence rate of 5.46 per 100,000 person-years and a prevalence rate of 20.57 per 100,000 . The population-based incidence rate of CRPS I in the Netherlands was $26.2 \%$ per 100,000 person-years with a peak incidence at 61-70 years of age [6]. The age-related increasing incidence rate of CRPS $\mathrm{I}$ is due to a higher incidence of fracture in older age. Postmenopausal woman appeared to be at the highest risk for the development of CRPS I. In a recent prospective study of $596 \mathrm{pa-}$ tients with fractures [7], 7\% of the patients developed CRPS I and none of the patients were free of symptoms at a 1-year follow-up. The lower incidence of the development of CRPS I in the present study might be explained by the use of diagnostic criteria with a higher specificity $(0,94)$. Only few patients develop CRPS I after distal radius fracture. A few genetic studies performed in CRPS I suggested that genetic factors may play a role in the pathophysiology of CRPS I. Early genetic studies revealed associations of CRPS I with class II (HLA-DQ1, HLA-DR15) (MHC) antigens $[8,9]$ and of CRPS I that progressed towards multifocal or generalized dystonia with HLA-DR13 allele [10]. Two distinct microsatellite loci contribute to the genetic predisposition to CRPS I with multifocal or generalized tonic dystonia [11]. Associations of HLA-DQ8 with both CRPS I with and CRPS I without dystonia, and of HLA-B62 only with CRPS I with dystonia, suggest that CRPS I patients with and without dystonia are genetically different $[12,13]$. Also CRPS I may show familial occurrence which suggests a genetic predisposition to develop CRPS I [14].

\section{Pathophysiologic Mechanisms of CRPS I}

The pathogenesis of CRPS I seems to be multifactorial. The mechanisms contributing to CRPS I differ from patient to patient and, even in the same patient, change over time. There are a number of different mechanisms accepted and documented in the literature [15].

\section{Autonomic Nervous System Dysfunction}

The traditional concept of sympathetic dysfunction in CRPS I speculates that the autonomic sympathetic hyperactivity in response to the heightened afferent activity from the damaged area caused pain, increased sweating, trophic changes, and vasoconstriction-related coldness $[16,17]$. However, the involvement of the sympathetic nervous system in the pathogenesis of CRPS I differs from classic theory [18]. Intraneural recordings have not evidenced an increased sympathetic neural discharge to the skin and catecholamine levels in serum are lower in the affected limb than in the unaffected limb [19-23]. The role of the sympathetic nervous system in the development and maintenance of symptomatology is not an excessive sympathetic outflow to the skin, but rather an increased sensitivity of blood vessels to catecholamines and the development of the adrenergic sensitivity by nociceptive neurons [19]. Nociceptive afferents develop adrenergic responsiveness following nerve trauma or tissue trauma associated with inflammation. This coupling between sympathetic postganglionic neurons and afferent neurons is mediated by $\alpha$-adrenoceptors [24]. In fact, the expression of $\alpha_{2}$-adrenoceptors mRNA is upregulated in DRG neurons following peripheral nerve injury or inflammation in a neuropathic pain model, and the expression of cutaneous $\alpha_{1}-\mathrm{AR}$ is increased bilaterally in the dermal nerves and keratinocytes of patients with CRPS I [25-27]. Furthermore, the intradermal injection of norepinephrine in patients with CRPS I and SMP on affected limbs caused a dose-dependent increase in pain once the patient had achieved pain relief following a sympathetic ganglion block [28].

\section{The role of Inflammatory Factors}

Especially in the acute phase, the CRPS I affected limb often displays the classic signs of inflammation (redness, heat, swelling) that suggest a local inflammatory process. Classic inflammation is characterized by typical immune cells such as lymphocytes, phagocytes, and mastcells, which secrete pro-inflammatory cytokines [29]. CRPS I patients display significant increases in proinflammatory cytokines (TNF- $\alpha$, IL-1 $\beta$, IL-2, IL-6) locally, in the blood plasma and in the cerebrospinal fluid. However, these patients manifest reduced systemic levels of anti-inflammatory cytokines (IL-10) when compared to controls [15, 29-34]. Additionally, there is an enhanced migration of injected radiolabeled autologous leukocytes or nonspecific immunoglobulins towards the acute CRPS I affected location $[35,36]$. Pro-inflammatory cytokines can excite nociceptors and induce long-term peripheral sensitization and have been shown to increase the release of calcitonin-gene-related peptide (CGRP) from primary afferent neurons $[32,37]$. It is postulated that the systemic pro-inflammatory observed cytokine profile may be a crucial factor in the pathogenesis of CRPS I [32]. Moreover, the sympathetic-afferent coupling may sensitize the nociceptive primary afferents and lead to the release of neuropeptides (Substance P and CGRP) from peptidergic unmyelinated fibers $[24,38]$. Neuropeptides (SP and CGRP) are released from the nerve endings in the skin and consequently 
evoke vasodilation and protein extravasation in the tissue, and the resulting signs (reddening, warming and edema) are called neurogenic inflammation [37]. Neurogenic vasodilation is generally more intensive on the controlateral unaffected limbs in CRPS I patients than healthy subjects [39]. This suggests that facilitated neurogenic inflammation might be one predisposing factor for CRPS I. The importance of neuropeptides for CRPS I pathophysiology is further underlined by the recent finding that CRPS I is associated with ACE-inhibitor therapy [40]. ACE metabolizes the neuropeptides SP and bradykinin to inactive forms, thus ACE inhibitors may lead to higher tissue levels of both neuropeptides. Their use is associated with an increased risk of CRPS I. Furthermore, previous data have demonstrated elevated systemic CGRP and SP levels in patients with acute CRPS I, and that neurogenic inflammation contributes to the clinical manifestation of acute CRPS I [41, 44]. The important contribution of inflammation to CRPS I is underlined by open-label studies on treatments with infliximab (anti-TNF) [45-46] and thalidomide [47]. Additionally, oral prednisone was significantly more effective than the placebo [48]; oral prednisolone resulted in significant improvement in the symptoms and signs of CRPS I following a stroke, when compared to piroxicam [49] and methylprednisolone had anti-edematous effects in a rat CRPS I model [50]. Endothelial dysfunction has been demonstrated in chronic stages of CRPS I. In cold type CRPS I patients, peripheral vasoconstriction could enhance tissue hypoxia and tissue acidosis. The production of free radicals within the ischemic limb may be responsible for the endothelial dysfunction observed in CRPS I patients [51]. Impaired endothelial function in chronic CRPS I plays a major role in the pathogenesis of trophic changes observed in both the superficial and deep tissues. Furthermore, tissue acidosis is followed by sensitization and most likely the activation of nociceptive afferents, which is followed by a spontaneous pain sensation [51].

\section{Central Sensitization}

The activity of nociceptive afferents will trigger a central sensitization process, which will be responsible for the development of allodynia and hyperalgesia [51]. Central sensitization is a state of CNS neuronal hyperactivity due to increased nociceptive input, particularly at the dorsal horn level of the spinal cord [52]. This process may play a crucial role in the pathogenesis of chronic pain and is the driving factor for CRPS I [53]. Central sensitization results in exaggerated responses to nociceptive stimuli (hyperalgesia) and permits normally nonpainful stimuli, such as light contact on the skin or cold, to become painful (allodynia) [29]. 'Windup' refers to the progressive increase in the magnitude of C-fiber evoked responses of dorsal horn neurons produced by repetitive activation of $\mathrm{C}$-fibers [54]. Temporal summation of repeated painful stimuli has been regarded as a psychophysical correlate of windup [55]. CRPS I patients display significantly greater temporal summation of pain in response to repeated mechanical stimuli applied to the affected limb than on the controlateral or other limbs. A marked mechanical hyperalgesia to brief impact stimuli (dynamic mechanical hyperalgesia) and to repetitive impact stimuli (windup) are arguments in favor of the strong central component in CRPS I pathogenesis [56]. N-methyl D-aspartate (NMDA) receptors play a critical role in central sensitization [53, $57,58]$.

\section{The Role of Glia Activation}

Spinal cord glia activation plays a major role in driving exagger- ated pain states, including CRPS I [59, 60]. Activated glia drive the creation and maintenance of allodynia and hyperalgesia. On activation, the glia release a number of substances that potentiate pain transmission by neurons [61]. These substances include pro-inflammatory cytokines, nitric oxide, excitatory amino acids, prostaglandins and ATP [59]. Indeed, elevated levels of the proinflammatory cytokines interleukin-6 (IL-6) and interleukin-1 $\beta$ (IL-1 $\beta$ ), of glial fibrillary acidic protein (GFAP), MCP1, NO metabolites, glutamate and calcium have been found in the cerebrospinal fluid (CSF) of patients afflicted with CRPS I [62] .

\section{Cortical Reorganization}

This syndrome is considered a disease of the central nervous system (CNS). It is speculated that the sensory, somatomotor and autonomic changes observed in patients with CRPS, in particular those with CRPS I, are the result of an abnormal information processing in the central nervous system and of plastic changes involving the autonomic nervous system, the somatomotor system and the somatosensory system [63]. The persistent activity of nociceptive primary neurons generates plastic changes in the primary somatosensory cortex (SI). Cortical reorganization is not restricted to the lesion of the afferent nervous system, because shifts of cortical somatotopic maps have also been demonstrated in cases of non-amputation-related pain [64]. In a recent study, magnetoencefalography (MEG) was used to assess cortical reorganization in the primary somatosensory cortex (SI), during acute CRPS I. A reduction in the size of the region representing the hand has been found and the cortical area representation of the affected hand has moved to a more lateral and inferior position towards the lower lip. This cortical reorganization appears to be correlated with the amount of CRPS pain and the extent of mechanical hyperalgesia [64]. These SI changes were reversed following successful treatment and recovery from CRPS I [65]. In addition, referred sensations and hemisensory deficits in patients with CRPS I provide further evidence of central sensory reorganization in such patients [66-68]. Furthermore, adaptive cortical changes within the motor system may occur in CRPS I and it has been shown that activation of the posterior parietal cortices, primary motor and supplementary cortices are correlated with the extent of motor dysfunction [69]. Excitability changes in the motor cortex were identified with transcranial magnetic stimulation. A significant reduction of intracortical inhibition was found in both hemispheres [70]. A recent controlled study supports a discrepancy between central motor output and sensory imput as underlying mechanism in CRPS I [71]. Mirror therapy is thought to reconcile motor output and sensory feedback [72]. A motor imagery program, consisting of hand laterality recognition followed by imagined movements and then mirror movements, reduced pain and disability in CRPS I patients [73]. The effect of the motor imagery program is not due to sustained attention to the affected limb but is consistent with sequential activation of cortical motor networks [74].

\section{Psychological Factors}

It has been hypothesized that the presence of a psychiatric disorder, particularly anxiety or depression, and life stressors may predispose one to develop CRPS I. Patients with CRPS I are more anxious and depressed than healthy control individuals, but the popular presumption that anxiety and depression predispose to CRPS I is incorrect [37] as psychological factors and personality traits are not factors that predispose an individual to develop 
CRPS I [2]. In a retrospective study psychological factors were not associated with CRPS I onset [75]. Being observational, this study should be interpreted in the light of its limitations. Prospective studies are required. In a large prospective study of 748 patients with fracture, psychological factors did not predict the development of CRPS I [76] and two recent reviews have not identified any relationship between psychological factors and the development of CRPS I [79, 80]. Negative outcomes of CRPS I are both psychological (e.g. increased depression and anxiety) and psychosocial (e.g. reduced quality of life, impaired occupational function) in nature. Psychological factors such as emotional distress (e.g. anxiety, depression) could potentially exacerbate vasomotor signs of CRPS I (via up-regulated adrenergic receptors) and directly increase pain intensity (via adrenergic receptors sprouting on nociceptive fibers post-injury) [34].

\section{Discussion}

Complex regional pain syndrome Type I is a chronic painful disorder that usually develops after a trauma to a limb, without an obvious peripheral nerve damage. Fractures, contusions, distortions and elective surgery are the most common triggers. In a large prospective study of 596 patients with fracture the incidence rate of the diagnosis of CRPS I based on the Harden and Bruehl criteria was $7.0 \%$ [7]. In 10\% of cases, CRPS I develops spontaneously [77]. CRPS I is a "complex" disorder in terms of its pathophysiology, diagnosis and treatment. The CRPS I has a multifactorial pathogenesis that can not be explained with a single mechanism, such as peripheral inflammation or sympathetic-afferent coupling [34]. The complexity and diversity of the mechanisms involved will be liable to the heterogeneity of the clinical presentation and may explain the difficulty of achieving an evidence-based treatment of CRPS I [78]. Enhanced understanding of the pathophysiology of CRPS I increases the possibility to develop mechanism-based treatments [34]. The main question is why do some people develop CRPS I and other people, with similar traumas do not? [81]. Genetic factors have been hypothesized to increase susceptibility to CRPS I in some individuals and a few genetic studies suggest that possible susceptibility genes reside in the Human Leukocyte Antigen (HLA) complex on the short arm of chromosome $6[8,9,11]$. Indeed it is now over forty years since the first associations between particular HLA antigens and disease susceptibility were described [82, 83]. An increased genetic predisposition could explain why some patients develop the syndrome without an eliciting event. There is an open debate whether the CRPS I can be considered a neuropathic pain syndrome in the light of recent definition of neuropathic pain [84, 85]. Although CRPS I is defined by the absence of major nerve lesion, Oaklander et al. [86] demonstrated a focal small-fiber axonal degeneration in the CRPS-affected skin sites. Albrecht et al. [87] reported decreased C-fiber and A $\delta$-fiber density in the affected limbs of CRPS I patients compared with nonpainful control sites on the same extremity and compared with healthy controls. Both studies indicate that CRPS I can be associated with pathological peripheral changes of the afferent innervation of the skin and, thus, support the hypothesis that CRPS I is a neuropathic condition, and that small-fiber axonal damage is involved in pathogenesis. In addition, several sensory phenomena of CRPS I patients are very similar to those present in other neuropathic pain disorders (e.g. postherpetic neuralgia or painful diabetic neuropathy). There is convincing evidence for facilitated neurogenic inflammation [41, 89], endothelial dysfunction [51], pathological sympatheticafferent coupling [89-91] and cortical changes [63]. The coupling between sympathetic postganglionic neurons and primary afferent neurons is the underlying mechanism of SMP. It is likely to be located within the skin as predicted by the pain-enhancing effect of intracutaneous norepinephrine injections [28]. This coupling may occur not only in the skin but also in deep somatic tissues, such as bone, muscles, or joints which are especially painful in some patients with CRPS I. Besides the direct coupling mediated by adrenoceptors, it may also occur indirectly, via the vascular bed or the immune system [38]. The decrease of sympathetic outflow to the affected limb leads to an increase of skin blood flow in arteriovenous anastomoses and to impairment of nutritive blood flow $[21,92]$. This means that there is skin hypoxia and acidosis [92]. The emerging protons are powerful algesic substances and cause pain in 'acute' CRPS I. Research in the last decade has focused on two mechanisms: posttraumatic inflammation in acute CRPS I and cortical reorganization mainly later. Increasing evidence indicates that CRPS I is the result of an exaggerated regional inflammatory response to injury or surgical procedure and that inflammatory processes are involved in the pathogenesis of early CRPS I [33, 44]. Clinical trials have shown that free radical scavengers can reduce signs and symptoms of CRPS I, indirectly suggesting that free radicals and increased oxidative stress are involved in the pathogenesis of CRPS I [93-95]. Recently other studies have indicated a role of the immune system in CRPS I $[96,97]$. The hypothesis that an autoimmune mechanism could be involved in the pathogenesis of CRPS I has been suggested by the following findings: IgG antibodies transferred from a patient with CRPS I to a group of mice (passive transfer) have induced a significant depression of rearing behavior [98]; moreover, treatment with intravenous immunoglobulin reduces pain in patients with CRPS I [99]. Recently, reorganization of somatotopic maps within the primary somatosensory cortex has been shown in CRPS I patients, using functional neuroimaging techniques [64, 65, 100-102]. In CRPS I and other neuropathic syndromes, cortical reorganization correlates with the amount of pain $[65,102$, 103]. CRPS I patients also show reorganization of central motor circuits $[69,104]$. Cortical reorganization may be reversed by a successful treatment $[64,67,102]$. The present results suggest that, when pain persists, reorganization in the brain may actually contribute to chronic pain which may significantly alter central tactile and motor processing in CRPS I patients [103, 105]. Based on all these findings, mirror therapy and graded motor imagery have been proposed at restoring the integrity of neural processing in the sensory-motor cortex in individuals with CRPS I [73, 106, 107]. In fact, the mismatch between motor intention and sensory feedback of the moving limb may generate pain in CRPS I and neurorehabilitative strategies have proved to be effective also in pain reduction $[100,106,108,109]$.

\section{Summary}

CRPS I is a complication occurring in an extremity, mostly following a minor injury or surgery. Acute CRPS I is considered a peripheral disorder, but chronic CRPS I is now widely established to be a central nervous system disease [110]. Persistent nociceptive CNS inputs, due to peripheral mechanisms such as neurogenic or classic inflammation, induce plastic changes in central network of tactile perception and motor control. Disruption of body-related representations promotes pain perception, being at least cause and not only consequence of chronic pain in patients with CRPS I [100, 111]. 


\section{References}

[1]. Dommerholt J (2004) Complex Regional Pain Syndrome 1: history, diagnostic criteria and etiology. Journal of Bodywork and Movement Therapies 8(3): 167-177.

[2]. Raja SN, Grabow TS (2002) Complex Regional Pain Sindrome I (Reflex Sympathetic Dystrophy). Anesthesiology 96(5): 1254-1260.

[3]. Stanton-Hicks M, Janig W, Hassembusch S, Haddox JD, Boas R, el al. (1995) Reflex sympathetic dystrophy: changing concepts and taxonomy. Pain 63(1): 127-133

[4]. Allen G, Galer BS, Schwartz L (1999) Epidemiology of complex regional pain syndrome: a retrospective chart review of 134 patients. Pain 80(3): 539-544.

[5]. Sandroni P, Benrud-Larson LM, McClelland RL, Low PA (2003) Complex regional pain syndrome type I: incidence and prevalence in Olmsted county, a population-based study. Pain 103(1-2): 199-207.

[6]. de Mos M, de Bruijn AG, Huygen FJ, Dieleman JP, Stricker BH, et al. (2007) The incidence of complex regional pain syndrome: a populationbased study. Pain 129(1-2): 12-20.

[7]. Beerthuizen A, Stronks DL, Van't Spijker A, Yaksh A, Hanraets BM, et al. (2012) Demografic and medical parameters in the development of complex regional pain syndrome type I (CRPS1): prospective study on 596 patients with a fracture. Pain 153(6): 1187-1192.

[8]. Mailis A, Wode J (1994) Profile of Caucasian women with possible genetic predisposition to reflex sympathetic dystrophy: a pilot study. Clin J Pain 10(3): 210-217.

[9]. Kemler MA, van de Vussue AC, van den Berg-Loonem EM, Barendse GA, van Kleef M, et al. (1999) HLA-DQ1 associated with reflex sympathetic dystrophy. Neurology 53(6): 1350-1351.

[10]. Van Hilten JJ, van de Beek WJ, Roep BO (2000) Multifocal or generalized tonic dystonia of complex regional pain syndrome: a distinct clinical entity associated with HLA-DR13. Ann Neurol 48(1): 113-116.

[11]. Van de Beek WJ, Roep BO, van der Slik AR, Giphart MJ, van Hilten BJ (2003) Susceptibility loci for complex regional pain syndrome. Pain 103(1): 93-97.

[12]. de Rooij AM, Gosso MF, Haasnoot GW, Marinus J, Verduijn W, et al. (2009) HLA-B62 and HLA-DQ8 are associated with complex regional pain syndrome with fixed dystonia. Pain 145(1): 82-85.

[13]. van Rooijen DE, Roelen DL, Verduijn W, Haasnnot GW, Huygen FJ, et al. (2012) Genetic HLA associations in complex regional pain syndrome with and without dystonia. J Pain 13(8): 784-789.

[14]. de Rooij AM, de Mos M, Sturkenboom MC, Marinus J, van den Maagdenberg AM, et al. (2009) Familial occurence of complex regional pain syndrome. Eur J Pain 13(2): 171-177.

[15]. Shah A, Kirchner JS (2011) Complex regional pain syndrome. Foot Ankle Clin 16(2): 351-366.

[16]. van der Laan L, Goris J (1997) Reflex sympathetic dystrophy. An exaggerated regional inflammatory response? Hand Clinics 13(3): 373-385.

[17]. Kurvers HA (1998) Reflex sympathetic dystrophy: facts and hypotheses. Vasc Med 3(3): 207-214

[18]. Pham T, Lafforgue P (2003) Reflex sympathetic syndrome and neuromediators. Joint Bone Spine 70(1): 12-17.

[19]. Casale R, Elam M (1992) Normal sympathetic nerve activity in a reflex sympathetic dystrophy with marked skin vasoconstriction. J Auton Nerv Syst 41(3): 215-219.

[20]. Casale R, Buonocore M (1993) Intraneural recordings do not support the hypothesis of an abnormal sympathetic nerve activity in reflex sympathetic dystrophy. Functional Neurology 6: 79-84.

[21]. Drummond PD (2001) Mechanism of complex regional pain syndrome: no longer excessive sympathetic outflow? Lancet 358(9277): 168-170.

[22]. Elam M (1997) Is reflex sympathetic dystrophy a valid concept? Behav Brain Sci 20(3): 447-448.

[23]. Drummond PD, Finch PM, Smythe GA (1991) Reflex sympathetic dystrophy: the significance of differing plasma catecholamine concentrations in affected and unaffected limbs. Brain 114(Pt 5): 2025-2036.

[24]. Janig W, Levine JD, Michaelis M (1995) Interactions of sympathetic and primary afferent neurons following nerve injury and tissue trauma. Prog Brain Res 113: 161-184

[25]. Shi TS, Winzer-Serhan U, Leslie F, Hokfelt T (2000) Distribution and regulation of a 2 -adrenoceptors in rat dorsal root ganglia. Pain $84(2-3)$ : 319-330.

[26]. Drummond PD, Skipworth S, Finch PM (1996) alpha 1-adrenoceptors in normal and hyperalgesic human skin. Clin Sci 91(1): 73-77.

[27]. Finch PM, Drummond ES, Dawson LF, Phillips JK, Drummond PD (2014) Up-regulation of cutaneous a1-adrenoceptors in complex regional pain syndrome type I. Pain Med 15(11): 1945-1956

[28]. Ali Z, Raja SN, Wesselmann U, Fuchs PN, Meyer RA, et al. (2000) Intradermal injection of norepinefrina evokes pain in patients with sympatheti- cally maintened pain. Pain 88(2): 161-168

[29]. de Mos M, Sturkenboom MC, Huygen FJ (2009) Current understandings on complex regional pain syndrome. Pain Pract 9(2): 86-99.

[30]. Huygen FJ, De Bruijn AG, De Bruin MT, Groeneweg JG, Klein J, et al. (2002) Evidence for local inflammation in complex regional pain syndrome type I. Mediators Inflamm 11(1): 47-51.

[31]. Alexander GM, van Rijn MA, van Hilten JJ, Perreault MJ, Schwartzman RJ (2005) Changes in cerebrospinal fluid levels of pro-inflammatory cytokines in CRPS. Pain 116(3): 213-219.

[32]. Uceyler N, Eberle T, Rolke R, Birklein F, Sommer C (2007) Differential expression patterns of cytokines in complex regional pain syndrome. Pain 132(1-2): 195-205.

[33]. Parkitny L, McAuley JH, Di Pietro F, Stanton R, O'Connell NE, et al. (2013) Inflammation in complex regional pain syndrome: a systematic review and meta-analysis. Neurology 80(1): 106-117.

[34]. Bruehl S (2010) An update on the pathophysiology of complex regional pain syndrome. Anesthesiology 113(3): 713-725.

[35]. Tan EC, Oyen WJ, Goris RJ (2005) Leukocytes in complex regional pain syndrome type I. Inflammation 29(4-6): 182-186.

[36]. Okudan B, Celik C (2006) Determination of inflammation of reflex sympathetic dystrophy at early stages with Tc-99m HIG scintigraphy: preliminary results. Rheumatol Int 26(5): 404-408.

[37]. Marinus J, Moseley GL, Birklein F, Baron R, Maihofner C, et al. (2011) Clinical features and pathophysiology of complex regional pain syndrome. Lancet Neurol 10(7): 637-648.

[38]. Janig W, Baron R (2003) Complex regional pain syndrome: mystery explained? Lancet Neurol 2(11): 687-697.

[39]. Leis S, Weber M, Schmelz M, Birklein F (2004) Facilitated neurogenic inflammation in unaffected limbs of patients with complex regional pain syndrome. Neurosci Lett 359(3): 163-166.

[40]. de Mos M, Huygen FJ, Stricker BH, Dieleman JP, Sturkenboom MC (2009) The association between ACE inhibitors and the complex regional pain syndrome: suggestions for a neuro-inflammatory pathogenesis of CRPS. Pain 142(3): 218-224

[41]. Birklein F, Schelmz M, Schiffer S, Wiber M (2001) The important role of neuropeptides in complex regional pain syndrome. Neurology $57(12)$ 2179-2184.

[42]. Schinkel C, Gaertner A, Zaspel J, Zedler S, Faist E et al. (2006) Inflammatory mediators are altered in the acute phase of posttraumatic complex regional pain syndrome. Clin J Pain 22(3): 235-239.

[43]. Birklein F, Schmelz M (2008) Neuropeptides, neurogenic inflammation and complex regional pain syndrome (CRPS). Neurosci Lett 437(3): 199-202.

[44]. Taha R, Blaise G (2007) Is complex regional pain syndrome an inflammatory process? Theories and therapeutic implications. Can J Anesth 54(4): 249-253.

[45]. Huygen FJ, Niehof S, Zijlstra FJ, van Hagen PM, van Daele PL (2004) Successful treatment of CRPS 1 with anti-TNF. J Pain Symptom Manage 27(2): 101-103.

[46]. Bernateck M, Rolke R, Birklein F, Treede RD, Fink M, et al. (2007) Successful intravenous regional block with low-dose tumor necrosis factor-alfa antibody infliximab for treatment of complex regional pain syndrome 1. Anesth Analg 105(4): 1148-1151.

[47]. Schwartzman RJ, Chevlen E, Bengtson K (2003) Thalidomide has activity in treating complex regional pain syndrome. Arch Intern Med 163(12): $1487-1488$.

[48]. Christensen K, Jensen EM, Noer I (1982) The reflex dystrophy syndrome response to treatment with systemic corticosteroids. Acta Chir Scand 148(8): 653-655.

[49]. Kalita J, Vajpayee A, Misra UK (2006) Comparison of prednisolone with piroxicam in complex regional pain syndrome following stroke: a randomized controlled trial. QJM 99(2): 89-95.

[50]. Guo TZ, Wei T, Kingery WS (2006) Glucocorticoid inhibition of vascular abnormalities in a tibia fracture rat model of complex regional pain syndrome type I. Pain 121(1-2): 158-167.

[51]. Schattschneider J, Hartung K, Stengel M, Ludwig J, Binder A, et al. (2006) Endothelial dysfunction in cold type complex regional pain syndrome. Neurology 67(4): 673-675.

[52]. Ji RR, Kohno T, Moore KA, Woolf CJ (2003) Central sensitization and LTP: do pain and memory share similar mechanisms? Trends Neurosci 26(12): 696-705.

[53]. Goebel A (2011) Complex regional pain syndrome in adults. Rheumatology 50(10): $1739-1750$

[54]. Woolf CJ (1996) Windup and central sensitization are not equivalent. Pain 66(2-3): 105-108

[55]. Eide PK (2000) Wind-up and the NMDA receptor complex from a clinical perspective. Eur J Pain 4(1): 5-15.

[56]. Sieweke N, Birklein F, Riedl B, Neundorfer B, Handwerker HO (1999) Patterns of hyperalgesia in complex regional pain syndrome. Pain 80(1): 
171-177.

[57]. Sigtermans MJ, Wan Hilten JJ, Bauer MC, Arbous MS, Marinus J, et al. (2009) Ketamine produces effective and long-term pain relief in patients with complex regional pain syndrome type I. Pain 145(3): 304-311.

[58]. Schwartzman RJ, Alexander GM, Grothusen JR, Paylor T, Reichenberger E, et al. (2009) Outpatient intravenous ketamine for the treatment of complex regional pain syndrome: a double-blind placebo controlled study. Pain 147(1): 107-115.

[59]. Watkins LR, Milligan ED, Maier SF (2001) Glial activation: a driving force for pathological pain. Trends Neurosci 24(8): 450-455.

[60]. Milligan ED, Watkins LR (2009) Pathological and protective roles of glia in chronic pain. Nat Rev Neurosci 10(1): 23-36.

[61]. Watkins LR, Maier SF (2003) Glia: a novel drug discovery target for clinical pain. Nat Rev Drug Discov 2(12): 973-985.

[62]. Alexander GM, Perreault MJ, Reichenberg ER, Schwartzam RJ (2007) Changes in immune and glial markers in the CSF of patients with complex regional pain syndrome. Brain Behav and Immun 21(5): 668-676.

[63]. Janig W, Baron R (2002) Complex regional pain syndrome is a disease of the central nervous system. Clin Auton Res 12(3): 150-164.

[64]. Maihofner C, Handwerker HO, Neundorfer B, Birklein F (2003) Patterns of cortical reorganization in complex regional pain syndrome. Neurology 61(12): 1707-1715

[65]. Maihofner C, Handwerker HO, Neundorfer B, Birklein F (2004) Cortical reorganization during recovery from complex regional pain syndrome. Neurology 63(4): 693-701

[66]. Rommel O, Gehling M, Dertwinkel R, Witscher K, Zenz M, et al. (1999) Hemisensory impairment in patients with complex regional pain syndrome. Pain 80(1-2): 95-101.

[67]. Rommel O, Malin JP, Zenz M, Janig W (2001) Quantitative sensory testing, neurophysiological and psychological examination in patients with complex regional pain syndrome and hemisensory deficits. Pain 93(3): 279-293.

[68]. McCabe CS, Haigh RC, Halligan PW, Blake DR (2003) Referred sensations in patients with complex regional pain syndrome type I. Rheumatology 42(9): 1067-73.

[69]. Maihofner C, Baron R, Decol R, Binder A, Birklein F, et al. (2007) The motor system shows adaptive changes in complex regional pain syndrome. Brain 130(Pt 10): 2671-2687.

[70]. Schwenkreis P, Janssen F, Rommel O, Pleger B, Völker B, et al. (2003) Bilateral motor cortex disinhibition in complex regional pain syndrome (CRPS) type I of the hand. Neurology 61(4): 515-519.

[71]. McCabe CS, Haigh RC, Ring EF, Halligan PW, Wall PD, et al. (2003) A controlled pilot study of the utility of mirror visual feedback in the treatment of complex regional pain syndrome (type I). Rheumatology 42(1): 97-101.

[72]. Moseley GL (2004) Why do people with complex regional pain syndrome take longer to recognize their affected hand? Neurology 62(12): 2182-2186.

[73]. Moseley GL (2006) Graded motor imagery for pathologic pain. Neurology 67(12): 2129-2134.

[74]. Moseley GL (2005) Is successful rehabilitation of complex regional pain syndrome due to sustained attention to the affected limb? A randomised clinical trial. Pain 114(1-2): 54-61.

[75]. De Mos M, Huygen FJ, Dieleman JP, Koopman JS, Stricker BH, et al. (2008) Medical history and the onset of complex regional pain syndrome (CRPS). Pain 139(2): 458-466.

[76]. Beerthuizen A, Stronks DL, Huygen FJ, Passchier J, Klein J, et al. (2011) The association between psychological factors and the development of complex regional pain syndrome type 1 (CRPS1) - A prospective multicenter study. Eur J Pain 15(9): 971-975.

[77]. Veldmann PH, Reynen HM, Arntz IE, Goris RJ (1993) Signs and symptoms of reflex sympathetic dystrophy: prospective study of 829 patients. Lancet 342(8878): 1012-1016.

[78]. Bussa M, Guttilla D, Lucia M, Mascaro A, Rinaldi S (2015) Complex regional pain syndrome type I: a comprehensive review. Acta Anaesthesiol Scand 59(6): 685-697.

[79]. Lohnberg JA, Altmaier EM (2013) A review of psychosocial factors in complex regional pain syndrome J Clin Psychol Med Settings 20(2): 247-254.

[80]. Beerthuizen A, Van't Spijker A, Huygen FJ, Klein J, de Wit R (2009) Is there an association between psychological factors and the complex regional pain syndrome type I (CRPS1) in adults? A systematic review. Pain 145(1-2): 52-59.

[81]. Vaneker M, van der Laan L, Allebers WA, Gorsi RJ (2002) Genetic factors associated with complex regional pain syndrome 1: HLA DRB and TNF alpha promotor gene polymorphism. Disabil Med 2: 69-74.

[82]. Howell WM (2014) HLA and disease: guilt by association. Int J Immunogenet 41(1): 1-12.

[83]. Ghodke Y, Joshi K, Chopra A, Patwardhan B (2005) HLA and disease. Eur J Epidemiol 20(6): 475-488.

[84]. Treede RD, Jensen TS, Campbell JN, Cruccu G, Dostrovsky JO, et al.
(2008) Neuropathic pain: redefinition and a grading system for clinical and research purpose. Neurology 70(18): 1630-1635.

[85]. Naleschinski D, Baron R (2010) Complex regional pain syndrome type I: neuropathic or not? Curr Pain Headache Rep 14(3): 196-202.

[86]. Oaklander AL, Rissmiller JG, Gelman LB, Zheng L, Chang Y, et al. (2006) Evidence of focal small-fiber axonal degeneration in complex regional pain syndrome-I (reflex sympathetic dystrophy). Pain 120(3): 235-243.

[87]. Albrecht PJ, Hines S, Eisenberg E, Pud D, Finlay DR, et al. (2006) Pathologic alterations of cutaneous innervation and vasculature in affected limbs from patients with complex regional pain syndrome. Pain 120(3): 244-266.

[88]. Weber M, Birklein F, Neundorfer B, Schmelz M (2001) Facilitated neurogenic inflammation in complex regional pain syndrome. Pain 91(3): 251 257.

[89]. Baron R, Field LH, Janig W, Kitt C, Levine JD (2002) National institutes of health workshop: reflex sympathetic dystrophy/complex regional pain syndrome - State of the Science. Anesth Analg 95(6): 1812-1816.

[90]. Schattschneider J, Binder A, Siebrecht D, Wasner G, Baron R (2006) Complex regional pain syndromes. The influence of cutaneous and deep somatic sympathetic innervation on pain. Clin J Pain 22(3): 240-244.

[91]. Baron R, Schattschneider J, Binder A, Siebrecht, Wasner G (2002) Relation between sympathetic vasoconstrictor activity and pain and hyperalgesia in complex regional pain syndromes: a case-control study. Lancet 359(9318): $1655-1660$

[92]. Koban M, Leis S, Schultze-Mosgau S, Birklein F (2003) Tissue hypoxia in complex regional pain syndrome. Pain 104(1-2): 149-157.

[93]. Zuurmond WW, Langendijk PN, Bezemer PD, Brink HE, de Lange JJ, et al. (1996) Treatment of acute reflex sympathetic with DMSO $50 \%$ in a fatty cream. Acta Anaesthesiol Scand 40(3): 364-367.

[94]. Gaspar M, Bovaira M, Carrera-Hueso FJ, Querol M, Jimenez A, el al. (2012) Efficacy of a topical treatment protocol with dimethyl sulfoxide 50\% in type 1 complex regional pain syndrome. Farm Hosp 36(5): 385-391.

[95]. Perez RS, Zuurmond WW, Bezemer PD, Kuik DJ, van Loenen AC (2003) The treatment of complex regional pain syndrome type I with free radical scavengers: a randomized controlled study. Pain 102(3): 297-307.

[96]. Goebel A, Blaes F (2013) Complex regional pain syndrome, prototype of a novel kind of autoimmune disease. Autoimmun Rev 12(6): 682-686.

[97]. Kohr D, Tschernatsch M, Schmitz K, Singh P, Kaps M, et al. (2009) Autoantibodies in complex regional pain syndrome bind to a differentiationdependent neuronal surface autoantigen. Pain 143(3): 246-251.

[98]. Goebel A, Leite MI, Yang L, Deacon R, Cendan CM, et al. (2011) The passive transfer of immunoglobulin $\mathrm{G}$ serum antibodies from patients with longstanding Complex Regional Pain Syndrome. Eur J Pain 15(5): 504 e1-504.e6.

[99]. Goebel A, Baranowski A, Maurer K, Ghiai A, McCabe C, et al. (2010) Intravenous immunoglobulin treatment of the complex regional pain syndrome: a randomized trial. Ann Intern Med 152(3): 152-158.

[100]. Schwenkreis P, Maier C, Tegenthoff M (2009) Functional imaging of central nervous system involvement in complex regional pain syndrome. Am J Neuroradiol 30(7): 1279-1284.

101]. Di Pietro F, McAuley JH, Parkitny L, Lotze M, Wand BM, et al. (2013) Primary somatosensory cortex function in complex regional pain syndrome: a systematic review and meta-analysis. J Pain 14(10): 1001-18.

[102]. Pleger B, Tegenthoff M, Ragert P, Forster AF, Dinse HR, et al. (2005) Sensorimotor returning in complex regional pain syndrome parallels pain reduction. Ann Neurol 57(3): 425-429.

[103]. Moseley GL, Flor H (2012) Targeting cortical representations in the treatment of chronic pain: a review. Neurorehabil Neural Repair 26(6): 646-652.

[104]. Di Pietro F, McAuley JH, Parkitny L, Lotze M, Wand BM, et al. (2013) Primary motor cortex function in complex regional pain syndrome: a systematic review and meta-analysis. J Pain 14(11): 1270-1288

[105]. Juottonen K, Gockel M, Silen T, Hurri H, Hari R, et al. (2002) Altered central sensorimotor processing in patients with complex regional pain syndrome. Pain 98(3): 315-323

[106]. Swart CM, Stins JF, Beek PJ (2009) Cortical changes in complex regional syndrome (CRPS). Eur J Pain 13(9): 902-907.

[107]. McCabe CS, Haigh RC, Blake DR (2008) Mirror visual feedback for the treatment of complex regional pain syndrome (Type I). Curr Pain Headache Rep12(2): 103-107.

[108]. Harris AJ (1999) Cortical origin of pathological pain. Lancet 354(9188): 1464-1466.

[109]. McCabe CS, Blake DR (2007) Evidence for a mismatch between the brain's movement control system and sensory as an explanation for some painrelated disorders. Curr Pain Headache Rep 11(2): 104-108.

[110]. Reinersmann A, Maier C, Schwenkreis, Leinz M (2013) Complex regiona pain syndrome: more than a peripheral disease. Pain Manag 3(6): 495-502.

[111]. Puretic MB, Demarin V (2012) Neuroplasticity mechanism in the pathophysiology of chronic pain. Acta Clin Croat 51(2): 425-429. 